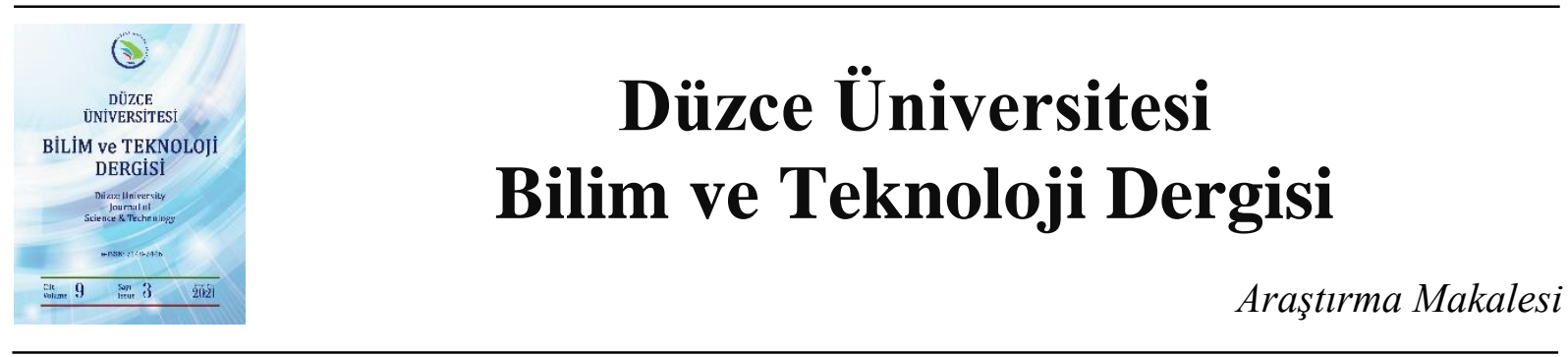

\section{Karar Destek Makineleri ve Rastgele Orman Ağaçları Yöntemleri ile Vücut Yă̆ Yüzdesinin Tahmini}

\author{
DiD Burhan BARAKLI ${ }^{\mathrm{a}}$, (D)Ahmet KÜÇÜKER ${ }^{\mathrm{a}, *}$ \\ ${ }^{a}$ Elektrik Elektronik Mühendisliği Bölümü, Mühendislik Fakültesi, Sakarya Üniversitesi, Sakarya, TÜRKIYYE \\ * Sorumlu yazarin e-posta adresi: kucuker@sakarya.edu.tr
}

DOI: $10.29130 /$ dubited. 815454

\begin{abstract}
ÖZET
Obezite, önemli bir sağlık problemidir ve yaygınlığı giderek artmaktadır. Bu hastalığın, diğer birçok hastalı̆̆ın tetikleyicisi ve habercisi olduğu bilinmektedir. Obezite hastalığının tedavi sürecinden önce, vücut yağ yüzdesinin doğru bir şekilde tespit edilmesi önemlidir. Yüksek maliyetli yöntemler ile vücut yağ yüzdesi kesin olarak ölçülmektedir. Bu çalışmada, kişilerden alınan antropometrik veri seti ile vücut yağı yüzdesi tespitinin doğru ve maliyetsiz bir şekilde tahmin edilebilmesi için destek vektör regresyonu ile rastgele orman ağaçları regresyon yöntemleri uygulanmıştır. Regresyon yöntemlerinde, model parametre değerleri, veri sayısı, özellik sayısı ve özellik seçimi tahmin başarımında önemlidir. 13 özellikli vücut yağ yüzdesi veri seti baz olarak alınan çalışmada, literatürde sıklıkla kullanılan 25 istatiski yöntem (çarpıklık, merkezi moment, basıklık vb.) ile yeni bir veri seti oluşturulmuş ve elde edilen yeni veri setinin başarım performansının literatürde yer alan diğer çalışmalardan yüksek olduğu görülmüsstür. Regresyon parametrelerinin izgara tarama yöntemleriyle belirlenmesi sayesinde tahmin doğrulukları arttırılmıştır. Ayrıca özellik azaltma yöntemleri ile vücut yağ yüzdesi ile yüksek ilintili özellikler belirlenmiştir. Seçilen özellikler ile gerçekleştirilen regresyon yöntemlerinin tahmin başarı performansının da benzer diğer çalışmalardan yüksek olduğu gözlenmiştir. En iyi ortalama karesel hata değerleri olarak, Rasgele Orman Ağaçları Yöntemi ve istatistiki yöntemle oluşturulan yeni veri seti ile gerçekleştirilen deneyde 2,2519 değeri elde edilirken, Karar Destek Makinaları ve en iyi 6 F-skor değerine sahip özellikler ile yapılan regresyon deneyinde 3,174 değerine ulaşılmıştır.
\end{abstract}

Anahtar Kelimeler: Vücut yă̆ yüzdesi, Destek vektör regresyonu, Rastgele orman ă̆açları regresyonu

\section{Estimation of Body Fat Percentage Using Support Vector Machine and Random Forest Methods}

\begin{abstract}
Obesity is a significant health problem, and its prevalence is increasing. It is known that this disease is the trigger and precursor of many other diseases. Before the treatment of obesity disease, it is important to determine the body fat percentage correctly. Body fat percentage can be measured precisely with high-cost methods. However, these methods are not common to use. In this study, support vector regression and random forest tree regression methods were applied to accurately and cost-effectively estimate body fat percentage with anthropometric data set taken from individuals. In regression methods, model parameter values, number of data, number of features and feature selection are important in prediction performance. In the study based on a 13 -featured body fat percentage data set, a new data set was created with 25 statistical methods (skewness, central moment, kurtosis, etc.) frequently used in the literature, and it was observed that the performance of the new data set was higher than other studies in the literature. Estimation accuracy has been increased by determining the regression parameters with grid scanning methods. In addition, features that are highly correlated with body fat percentage were determined with
\end{abstract}


feature reduction methods. It was observed that the prediction success performance of the regression methods performed with the selected features was higher than other similar studies. As the best mean square error values, the value of 2.2519 was obtained in the experiment performed with the Random Forest Trees Method and the new data set created by the statistical method, while the value of 3.174 was reached in the regression experiment with Decision Support Machines and the properties with the best $6 \mathrm{f}$-score values.

Keywords: Body fat percentage, Support vector regression, Random forest

Geliş: 23/10/2020, Düzeltme: 16/03/2021, Kabul: 25/03/2021

\section{GIRIS}

Çağımızın önemli hastalıkları arasında olan obezite, insan hayatını olumsuz etkileyen ve birçok ölümcül hastalığın oluşmasına neden olan ciddi bir sorundur [1]. Obezite, vücutta bulunan yağ kütlesinin, yağsız kütleye oranla aşırı miktarda artması olarak tanımlanmaktadır. Bu sağlık problemi hem çocuklarda hem de yetişkinlerde giderek artan bir seyir izlemektedir. Dolasıyla bireylere ve devletlere ekonomik bir yük getirmektedir [2].

Vücudun temel enerji kaynaklarından olan vücut yağlarının, vitaminlerin emilimi ve taşınması, vücut 1sısının ayarlanması, soğuğa karşı koruma ve hayati organları koruma gibi görevleri vardır. Vücut yağ miktarının yetersiz olması durumunda ise üşüme, vitaminsizlik, halsizlik, çabuk hastalanma ve hormonal dengesizlik gibi sorunlar ortaya çıkmaktadır. Vücut yağ miktarının fazla olması durumunda da obezite problemi, Tip 2 diyabet şeker hastalığı, hipertansiyon, kalp hastalıkları, kısırlık, eklem hastalığı olan osteoartrit (kireçlenme), safra kesesi taşı, karaciğer yağlanması, uyku apnesi, venöz (toplardamar yetmezliği), cilt hastalıkları, solonum zorlukları, depresyon ve bazı tümörler dahil olmak üzere bir dizi sağlık problemine sebep olmaktadır [3-4].

Hasta olan kişilerin bir şekilde izlenmesi veya hastalığın teşhisi için, obezitenin kesin ölçüm sonuçlarına ihtiyaç bulunmaktadır. Obezite, aşırı vücut yağı durumu olarak tanımlanır ve doğrudan herhangi bir niceliksel ölçüt oluşturmaz [5]. Kilo, vücut yağının basit bir niceliksel örneğidir ve ölçülmesi kolaydır, ancak kişinin genel yapısı hakkında bilgi olmadan neredeyse anlamsız bir niceliktir. Ancak vücuttan elde edilen farklı niceliksel bilgiler ile anlamlandırılabilecek tanımlamalar türetilmiştir. Örneğin Dünya Sağlık Örgütü tarafından kabul gören Vücut Kitle Endeksi (Body Mass Index (BMI)), vücut boy ve kilo bilgilerinin kullanılması ile formüle edilmiştir [6].

Obeziteyi ölçmek için yaygın olarak kullanılan BMI, ucuz ve uygun bir yoldur. Ancak BMI, yetersiz sayıda parametrelerden hesaplandığından sağlık sonuçlarını tahmin etmekte genellikle yetersiz performans göstermektedir [7]. Bel çevresi veya bel-kalça oranı gibi ilave parametreler ile BMI'ın yetersizlikleri giderilmeye çalışılmıştır [8]. Ayrıca BMI, yağ ve yağsız kütle arasında ayrım yapamayan beslenme durumunu göstermektedir [9]. Vücut yağı oranı ise, obeziteyi ölçmenin daha iyi bir yolu olan gerçek vücut kompozisyonu durumunu göstermektedir [10].

Vücut yağ kütlesinin kendisinin veya vücut yağ yüzdesinin (Body Fat Percentage (BFP)) doğrudan ölçümü daha iyi bir yaklaşım olmasına rağmen, ölçümü zordur ve geniş bir kullanım için uygun değildir. Doğru ölçüm yapan yöntemler arasında su altı tartımı [11,12], X-1şını absorpsiyometrisi [13], biyoelektrik empedans analizi [14], manyetik rezonans görüntüleme [15], havada yer değiştirme pletismografisi [16] ve yakın kızı̈ötesi etkileşim [17] gibi yöntemler bulunmaktadır. Ancak, bu yöntemler özel ekipman gerektirdiğinden, vücut yağının doğrudan ölçümü için zor, uygunsuz ve maliyetlidir. Bu nedenle, BFP'nin temel sosyodemografik veriler (yaş, cinsiyet), temel antropometrik veriler (ağırlık, boy, bel çevresi) ve rutin kan alımından elde edilen temel laboratuvar parametreleri gibi kolayca ölçülebilir parametrelerden tahmin edilebilmesi önemlidir [18-20]. 
BFP'nin tahminini bir regresyon problemi olarak ele alan birkaç çalışma bulunmaktadır. Bir tahmin modeli oluşturabilmek için kişinin yaşı, kilosu, boyu ve vücut çevresi gibi kolayca ölçülebilir özellikleri dikkate alan bir çalışma gerçekleştirilmiştir [21]. Destek vektör makinesi (Support Vector Machine (SVM)) kullanarak vücut yağını tahmin etmede etkili sonuçlar elde edilmiştir [22,23]. Yapay sinir ağlarını (YSA) [10,20] kullanarak yapılan çalışmalarda, BMI hesaplarını baz alan diğer çalışmalara [2425] göre yüksek başarım oranı gözlenmiştir. Daha az parametre ile BFP tahmini için iyi sonuçlar elde edebilen yeni akı1lı hibrit yaklaşımlar [26,27] tarafından önerilmiştir. Tıbbi cihazlardan, elektronik-tıbbi sağlık kayıtlarından, akıllı telefon uygulamalarından elde edilen verilerden BFP tahmini gerçekleştirilen bir çalışmada, lojistik regresyon, YSA ve karar ağacı dahil olmak üzere farklı makine öğrenme algoritmaları kullanılmıştır. Çalışmada regresyon tahmin modellerinin, BFP'nin tahmini için iyi performansa sahip olduğu belirtilmiştir [28]. Fotopletismografi ile elde edilen verilerden makine öğrenmesi yöntemleri kullanılarak BFP tahmininde etkili bir yöntem [29]'da sunulmuştur.

Literatürden elde edilen izlenim, regresyon yöntemlerinin uygun, maliyetsiz ve başarılı çıktılar ürettiğidir. Bu nedenle, bu çalışmada destek vektör regresyonu (SVR) [30] ve rastgele karar ağaçları (RF) [31] BFP'nin tespiti için kullanılmıştır. Gerçek bir veri tabanından elde edilen temel sosyodemografik veri seti (yaş, cinsiyet) ve temel antropometrik veri seti (ağırlık, boy, bel çevresi) ile BFP'in bu parametrelerden ne kadar iyi tahmin edilebileceği araştırılmıştır. Ayrıca orijinal veri setinden yeri özellikler çıkartılmış ve veri seti genişletilmiştir. BFP değerinin tahmini hem orijinal veri setinden hem de genişletilmiş veri setinden faydalanılarak tespit edilmeye çalışılmıştır. Bunların yanı sıra özellik seçimi ve özellik azaltımının regresyon yöntemlerinin başarısına olan katkısı incelenmiştir. Özellik seçimi için tek değişkenli doğrusal regresyon (TDDR) ve özellik azaltımı için ise temel bileşenler analizi (PCA) yöntemi uygulanmıştır.

\section{GEREC VE YÖNTEMLER}

BFP tahmini genel blok diyagramı Şekil 1 ile verilmiştir. Orijinal veri setine, veri seti artırımı ile oluşturulan veri setlerine iki farklı regresyon yöntemi uygulanmıştır. Regresyon başarımını arttırmak için en iyi parametre tahmini algoritmaları kullanılarak regresyon parametrelerin doğru seçilmesi hedeflenmiştir. Eğitim verisi ve test verisinin başarımını doğru elde edebilmek amacıyla k katmanlı çapraz doğrulama algoritması kullanılmıştır.

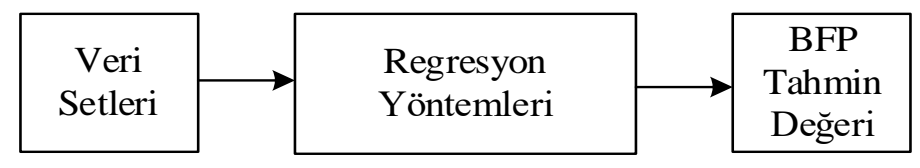

Şekil 1. Çalı̧̧anin organizasyonu

Bu çalışmada 252 kişiden elde edilen elde edilen 13 özellikli bir veri seti (vs1) üzerinde çalışılmıştır [32]. Ölçüm sonuçlarından elde edilen antropometrik verilerin (vs1=Tablo 1 [X1-X13]) açıklamaları Tablo 1'de verilmiştir. Veri setindeki BFP'nin belirlenmesi için [33]'ten yararlanılmıştır.

vs1'deki özellikler ve istatistik yöntemler uygulanarak 25 özellikli yeni bir veri seti (vs2=Tablo 1 [X14X38]) oluşturulmuştur. Üçüncü bir veri seti olan vs3 ise vs1 ve vs2 birleştirilerek elde edilmiştir.

Bir bağımsız ile bir bağımlı değişken arasındaki ilintiyi belirlemeye yarayan TDDR yöntemi (F-skor başarımı) kullanılarak, BFP ile ilgili özelliğin ilintisi Tablo 1'de üçüncü sütunda verilmiştir [34]. BFP ile ilintisi yüksek olan özellikler, vs1 veri setinde X6 adlı özellik (abdomen çevresi=karın çevresi) ve vs2 veri setinde ise dağılımın simetrik olup olmama derecesini belirten (çarpıklık) X15 adlı özellik olmuştur.

Orijinal veri seti vs1'in ikili özellikleri arasındaki ilişkinin dağılımı Şekil 2'de gösterilmiştir. Şekilden de görebileceği gibi farklı iki özellik birbiri ile ilişkilidir. Bazı ikili özellikler doğrusal olmayan bir 
şekilde ilişkili iken (örneğin, Bilek ve Yaş), çoğu özellik doğrusal olarak birbiri ile ilişkilidir (örneğin, Boyun ve Ağırlık, Göğüs ve Abdomen). Ek olarak, ağırlık özelliğinin diğer özelliklerle güçlü bir ilişkisi varken boy özelliği diğer özelliklerle daha zayıf ilişki göstermektedir.

Tablo 1. Veri setlerine ait özellikler

\begin{tabular}{|c|c|c|}
\hline Ad & Özellik & F-skor \\
\hline $\mathrm{X} 1$ & Yaş1 (Y1l) & 5.47 \\
\hline $\mathrm{X} 2$ & Boy $(\mathrm{cm})$ & 0.34 \\
\hline X3 & Ağırlık (kg) & 25.06 \\
\hline $\mathrm{X} 4$ & Boyun çevresi $(\mathrm{cm})$ & 15.31 \\
\hline $\mathrm{X} 5$ & Göğüs çevresi (cm) & 36.89 \\
\hline X6 & $\begin{array}{l}\text { Abdomen } \\
\text { çevresi }(\mathrm{cm})\end{array}$ & 56.68 \\
\hline $\mathrm{X7}$ & Kalça çevresi $(\mathrm{cm})$ & 25.99 \\
\hline $\mathrm{X} 8$ & Uyluk çevresi $(\mathrm{cm})$ & 19.21 \\
\hline X9 & Diz çevresi $(\mathrm{cm})$ & 15.69 \\
\hline X10 & $\begin{array}{l}\text { Ayak Bileği çev. } \\
(\mathrm{cm})\end{array}$ & 4.18 \\
\hline X11 & $\begin{array}{l}\text { Açık Kol Biceps } \\
\text { çevresi }(\mathrm{cm})\end{array}$ & 14.66 \\
\hline $\mathrm{X} 12$ & Ön kol çevresi $(\mathrm{cm})$ & 7.63 \\
\hline $\mathrm{X} 13$ & Bilek çevresi $(\mathrm{cm})$ & 7.47 \\
\hline $\mathrm{Y}$ & Vücut Yağ Yüzdesi & \\
\hline $\mathrm{X} 14$ & Kurtosis - Basıklık & 53.34 \\
\hline $\mathrm{X} 15$ & Skewness - Çarpıklık & 54.67 \\
\hline $\mathrm{X} 16$ & $\begin{array}{l}\text { Çeyrekler arası } \\
\text { genişlik }\end{array}$ & 45.49 \\
\hline $\mathrm{X} 17$ & Değişim Katsayısı & 25.18 \\
\hline $\mathrm{X} 18$ & Geometrik ortalama & 34.32 \\
\hline X19 & Harmonik ortalama & 28.01 \\
\hline $\mathrm{X} 20$ & $\begin{array}{l}\text { Hijort Aktivite } \\
\text { Katsayis1 }\end{array}$ & 10.06 \\
\hline
\end{tabular}

\begin{tabular}{clc}
\hline Ad & \multicolumn{1}{c}{ Özellik } & F-skor \\
\hline X21 & $\begin{array}{l}\text { Hijort Hareketlilik } \\
\text { Katsayıs }\end{array}$ & 18.28 \\
\hline X22 & $\begin{array}{l}\text { Hijort Karmaşıklık } \\
\text { Katsayıs1 }\end{array}$ & 12.26 \\
\hline X23 & Maksimum değeri & 0.34 \\
\hline X24 & Medyan değeri & 6.59 \\
\hline X25 & Mutlak Sapma & 24.72 \\
\hline X26 & Minimum değeri & 7.47 \\
\hline X27 & Merkezi Moment & 13.23 \\
\hline X28 & Ortalama değeri & 3.31 \\
\hline X29 & $\begin{array}{l}\text { Ortalama Eğri } \\
\text { Uzunluğu }\end{array}$ & 7.63 \\
\hline X30 & Ortalama Enerji & 27.79 \\
\hline X31 & $\begin{array}{l}\text { Ortalama Karakök } \\
\text { RMS değeri }\end{array}$ & 28.72 \\
\hline X32 & Standart hata \\
\hline X33 & Standart Sapma & 10.20 \\
\hline X34 & $\begin{array}{l}\text { Şekil Faktörü } \\
\text { X35 }\end{array}$ Tekil Değer Ayrışımı & 10.20 \\
\hline X36 & $\begin{array}{l}\text { "\%25" için kesilmiş } \\
\text { ortalama değeri }\end{array}$ \\
\hline X37 & $\begin{array}{l}\text { "\%50” için kesilmiş } \\
\text { ortalama değeri }\end{array}$ \\
\hline X38 & $\begin{array}{l}\text { 5 Ortalama Teager } \\
\text { Enerjisi }\end{array}$ \\
\hline & \multicolumn{1}{c}{41.02} \\
\hline
\end{tabular}

\section{A. TEK DEĞİŞKENLİ DOĞRUSAL REGRESYON ANALİZi}

Regresyon analizi yöntemi, değişkenler veya özellikler arasındaki ilintinin gücü ve yönü hakkında bilgi veren bir ölçüm yöntemidir. TDDG analizi [34] ise, bir bağımlı değişken ve bir bağımsız değişken arasındaki ilişkiyi sayısal olarak belirleyen bir analiz yöntemidir. Bu analizle bağımlı ve bağımsız değişkenler arasındaki ilişki bir doğru denklemi ile formüle edilmektedir. Vektör olarak verilen $X 1, X 2, \ldots, X M$ bağımsız değişkenler ve $Y 1, Y 2, \ldots, Y M$ bağımlı değişkenlerin her biri normal dağılıma sahip iki popülasyondan aynı şekilde dağıtılmış örnekler olmak üzere bir lineer regresyon hipotez fonksiyonu Eşt. 1. ile verilmektedir.

$$
h_{\theta}(x)=\theta_{1} x+\theta_{0}
$$

Eşt. 2'de $\theta$ parametrelerini optimum olarak hesaplayabilmek için bir maliyet fonksiyonu verilmiştir. Maliyet fonksiyonun minimum değerini hesaplamak amacıyla Bayır İniş Algoritması yöntemi [35] kullanılmış ve Eşt. 3'te verilmiştir. $\alpha$ öğrenme katsayısı ve $m$ örnek sayısı olmak üzere, amaç fonksiyonu $\theta_{0}{ }^{*}, \theta_{1}{ }^{*}=\underset{\theta_{0}, \theta_{1}}{\operatorname{argmin} J}\left(\theta_{0}, \theta_{1}\right)$ 'dır. 


$$
J\left(\theta_{0}, \theta_{1}\right)=\frac{1}{2 m} \sum_{i=0}^{m}\left(h\left(x^{(i)}\right)-y^{(i)}\right)^{2}
$$

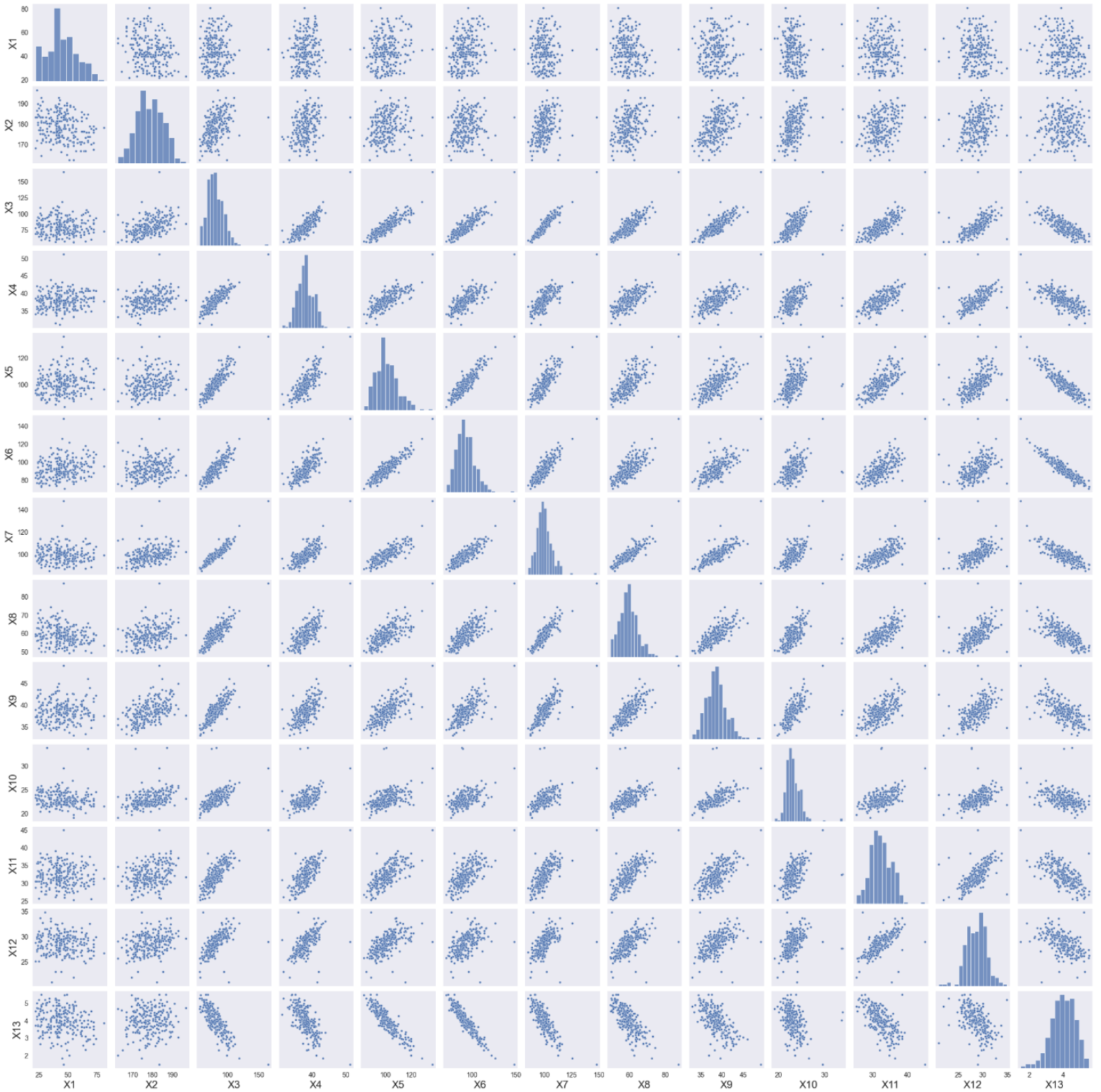

Sekil 2.vs1 veri seti ikili özellikler arası ilișki

Maliyet fonksiyonun minimum değeri hesaplanana kadar, Eşt. 3'teki $\theta_{0}$ ve $\theta_{1}$ parametreleri bir iterasyon ile elde edilir.

$$
\left(\theta_{0}, \theta_{1}\right) \leftarrow\left(\theta_{0}, \theta_{1}\right)-\alpha \frac{\partial\left(J\left(\theta_{0}, \theta_{1}\right)\right)}{\partial}
$$

$\mathrm{Bu}$ çalı̧̧mada giriş özelliklerinin çıkış değişkenine katkısını araştırmak amacıyla her bir özellik için doğrusal regresyon oluşturulmuş ve en optimum $y(x)=\theta_{1} x+\theta_{0}$ belirlenmiştir. Her özelliğe ait başarım için TGDD yöntemindeki F-skoru hesaplanmıştır. Özellik sayısı kolmak üzere, $\bar{X}[k]$ ve $\bar{Y}[k]$ ortalama değer dizileri, 
$\bar{X}[k]=\frac{1}{m} \sum_{i=1}^{m} X_{k}[i]$ ve $\bar{Y}[k]=\frac{1}{m} \sum_{i=1}^{m} Y_{k}[i]$

olarak Eşt. 4'teki gibi verilebilir. Varyans dizileri $S_{x}^{2}[k]$ ve $S_{y}^{2}[k]$ Eşt. 5.'te verilmiştir.

$S_{x}^{2}[k]=\frac{1}{m-1} \sum_{i=1}^{m}\left(X_{k}[i]-\bar{X}[k]\right)^{2}$ ve $S_{y}^{2}[k]=\frac{1}{m-1} \sum_{i=1}^{m}\left(Y_{k}[i]-\bar{Y}[k]\right)^{2}$

F-skoru Eşt. 6'daki gibi hesaplanır. Bu dizi, giriş özelliklerinin her biri için F-skor değerini vermektedir ve Tablo 1'de bu değerler üçüncü sütunda verilmektedir.

$$
F[k]=\frac{S_{x}^{2}[k]}{S_{y}^{2}[k]}
$$

\section{B. KARAR DESTEK MAKINESİ REGRESYONU (SVR)}

SVR çekirdek-tabanlı dönüşümlerde, giriş verileri yüksek boyutlu özellik uzaylarına taşınır ve bu uzayda doğrusal regresyon gerçekleştirilir.

Giriş verisi $\left\{\left(\boldsymbol{x}_{\boldsymbol{i}}, y i\right)\right\}_{i=1}^{N}$ olmak üzere, SVR yönteminin amaç ve kısıt ifadesi Eşt. 7 ile ifade edilir.

$$
\begin{gathered}
\underset{w, C, \varepsilon_{i}}{\operatorname{argmin}} \frac{1}{2}\langle\boldsymbol{w}, \boldsymbol{w}\rangle+C \sum_{i=1}^{n}\left(\varepsilon_{i}+\varepsilon_{i}^{*}\right) \\
\text { Kisit: }\left\{\begin{array}{c}
y_{i}-\left\langle\boldsymbol{w}, \boldsymbol{x}_{\boldsymbol{i}}\right\rangle-\theta_{0} \leq \varepsilon+\varepsilon_{i} \\
\left\langle\boldsymbol{w}, \boldsymbol{x}_{\boldsymbol{i}}\right\rangle+\theta_{0}-y_{i} \leq \varepsilon+\varepsilon_{i}{ }^{*} \\
\varepsilon_{i}, \varepsilon_{i}{ }^{*} \geq 0
\end{array}\right.
\end{gathered}
$$

Amaç fonksiyonundaki $C$ regülasyon parametresi, $\boldsymbol{w}=\left(\theta_{1},-1\right), \varepsilon$ esnek kenar pay1, $\varepsilon_{i}$ ve $\varepsilon_{i}{ }^{*}$ ise esnek değişkenlerdir. İki kısıtı olan doğrusal olmayan bir fonksiyonun çözümü için dual-çözüm önerilmektedir [36]. Dual çözüm için kullanılan Lagrange parametreleri, Eşt. 7'ye $(\alpha, \beta)$ parametrelerinin eklenmesiyle oluşan lagrange fonskiyonu Eşt. 8'deki gibi elde edilmektedir.

$$
\begin{aligned}
L:=\frac{1}{2}\langle\boldsymbol{w}, \boldsymbol{w}\rangle+ & C \sum_{i=1}^{n}\left(\varepsilon_{i}+\varepsilon_{i}{ }^{*}\right)-\sum_{i=1}^{n}\left(\beta_{i} \varepsilon_{i}+\beta_{i}{ }^{*} \varepsilon_{i}{ }^{*}\right)-\sum_{i=1}^{n} \alpha_{i}\left(\varepsilon+\varepsilon_{i}-\left\langle\boldsymbol{w}, \boldsymbol{x}_{\boldsymbol{i}}\right\rangle+\theta_{0}-y_{i}\right) \\
& -\sum_{i=1}^{n} \alpha_{i}{ }^{*}\left(\varepsilon+\varepsilon_{i}{ }^{*}+y_{i}-\left\langle\boldsymbol{w}, \boldsymbol{x}_{\boldsymbol{i}}\right\rangle-\theta_{0}\right)
\end{aligned}
$$

L fonksiyonunu en küçükleyen $\boldsymbol{w}, \theta_{0}, \varepsilon$ ve $\varepsilon_{i}{ }^{*}$ parametreleri için kısmi türevlerin alınıp, Eşt. 6 ' da yerine yazılırsa amaç ve kısıt fonksiyonu Eşt. 7'deki gibi oluşur.

$$
\left\{\begin{array}{l}
\max _{\alpha_{i}, \alpha_{i}{ }^{*}} L=\frac{1}{2} \sum_{i, j=1}^{n}\left(\alpha_{i}-\alpha_{i}{ }^{*}\right)\left(\alpha_{j}-\alpha_{j}{ }^{*}\right)\left\langle\boldsymbol{x}_{\boldsymbol{i}}, \boldsymbol{x}_{\boldsymbol{j}}\right\rangle-\varepsilon \sum_{i=1}^{n}\left(\alpha_{i}+\alpha_{i}{ }^{*}\right)+y_{i} \sum_{i=1}^{n}\left(\alpha_{i}-\alpha_{i}{ }^{*}\right) \\
\text { kısit fonksiyonu: } \sum_{i=1}^{n}\left(\alpha_{i}-\alpha_{i}^{*}\right)=0 \text { ve } \alpha_{i} \alpha_{i}^{*} \in[0, C]
\end{array}\right.
$$




$$
\begin{aligned}
& w=\sum_{i=1}^{n}\left(\alpha_{i}-\alpha_{i}^{*}\right) \boldsymbol{x}_{\boldsymbol{i}} \\
& f(x)=\sum_{i=1}^{n}\left(\alpha_{i}-\alpha_{i}^{*}\right)\left\langle\boldsymbol{x}_{\boldsymbol{i}}, \boldsymbol{x}_{\boldsymbol{j}}\right\rangle+\theta_{0}
\end{aligned}
$$

Eşt. 10 ve Eşt. 11 ile verilen denklemler doğrusal SVR olarak adlandırılmaktadır. Ancak, Eşt. 11 doğrusal olmayan problemlerin çözümünde uygun olmayan sonuçlar üretebilmektedir. Bu nedenle giriş özellikleri bir üst uzaya taşınmaktadır ve üst uzayda uygulanacak olan lineer regresyonlar daha başarılı sonuçlar vermektedir. $\emptyset: R^{2} \rightarrow R^{3}$ haritalamayı ve çekirdek hilesi olan $K\left(x_{i}, x\right)=\left\langle\emptyset_{x}, \emptyset_{y}\right\rangle$ olmak üzere, çekirdeğin Eşt. 10 ve Eşt. 11'de yerine yazılmasıyla doğrusal olmayan problemlerinde başarılı çıktılar üreten SVR regresyonu elde edilmektedir.

$$
\begin{aligned}
& w=\sum_{i=1}^{n}\left(\alpha_{i}-\alpha_{i}^{*}\right) \emptyset\left(\boldsymbol{x}_{\boldsymbol{i}}\right) \\
& f(x)=\sum_{i=1}^{n}\left(\alpha_{i}-\alpha_{i}^{*}\right) k\left\langle\boldsymbol{x}_{\boldsymbol{i}}, \boldsymbol{x}\right\rangle+\theta_{0}
\end{aligned}
$$

Bu çalışmada sıkça kullanılan ve doğrusal olmayan problemlerde başarılı sonuçlar veren Radial temelli fonksiyon (RBF) kullanılmıştır. RBF kerneli $k\left\langle\boldsymbol{x}_{\boldsymbol{i}}, \boldsymbol{x}\right\rangle=\exp \left(-\gamma\left\|\boldsymbol{x}_{\boldsymbol{i}}-\boldsymbol{x}_{\boldsymbol{j}}\right\|^{2}\right)$ olarak tanımlanmıştır.

\section{RASTGELE ORMAN AĞAÇLARI (RF) İLE REGRESYON}

Bir karar ağacı, hiyerarşik olarak organize edilmiş ve bir kökten ağacın bir uç düğümüne veya yaprağına arka arkaya uygulanan bir dizi kısıtlama veya koşulu temsil etmektedir [37]. Karar ağacı, bir kök dügümü ile başlar. Bu düğümde, karar ağacı öğrenme algoritmasına göre bölünmeler gerçekleşir. Nihai sonuç, her dalın olası bir karar senaryosu ve sonucunu temsil ettiği bir karar ağacıdır. RF yöntemi ise, birden fazla karar ağacını oluşturur ve daha doğru ve istikrarlı bir tahmin elde etmek için karar ağaçlarını birleştirilir [38]. RF ile bir $x$ değerine ait tahmini hesaplamak için, her bağımsız ağaç için Eşt. 14 kullanilır.

$$
\widehat{f_{r f}^{B}}(x)=\frac{1}{B} \sum_{b=1}^{B} T\left(x ; \Theta_{b}\right)
$$

$\Theta_{b}$, b inci rasgele orman ağacını, bölünmüş değişkenler, düğümlerdeki kesme noktalarını ve B ağaç sayısinı ifade eder.

\section{DENEYSEL CALISSMALAR ve SONUCLARI}

$\mathrm{Bu}$ çalışmada BFP değerinin regresyon yöntemleriyle tahmini için gerçek bir veri seti (vs1) kullanılmaktadır. Bu veri setinden ilk önce vs2 ve vs3 oluşturulmuş, ardından TGDD ve PCA yöntemleri ile BFP değeri ile yüksek ilintili belli sayıda özellikler seçilerek ve temel bileşenler belirlenerek 15 adet veri seti daha üretilmiştir. Veri setlerinin özeti Tablo 2'de açıklamıştır. Tablo 2'de verilen 18 veri setine SVR ve RF regresyon yöntemleri uygulanmaktadır. Örnek olarak, S3 adlı veri seti; 35 özellikli bir veri setidir. S11 adlı veri seti; vs1 veri setine PCA yöntemi uygulanarak elde edilen iki temel bileşen özelliğine sahip veri seti ve S15 ise vs2 veri setindeki F-skor değeri en iyi olan ilk 6 değişken özellikli bir veri setidir. 
BFP tahmini için oluşturulan regresyon çalışmasının blok akış şeması Şekil 3'te verilmiştir. Regresyon yöntemlerinde eğitim parametrelerinin değerleri önemlidir. $\mathrm{Bu}$ nedenle en uygun regresyon parametrelerinin belirlenmesi için bir yöntem gereklidir. $\mathrm{Bu}$ amaçla, bir döngü oluşturularak (grid arama) regresyonlara ait en iyi sonucu veren parametreler belirlenmiş ve regresyon yöntemleri $20 \mathrm{kez}$ koşturularak, sonuçların ortalaması alınmıştır.

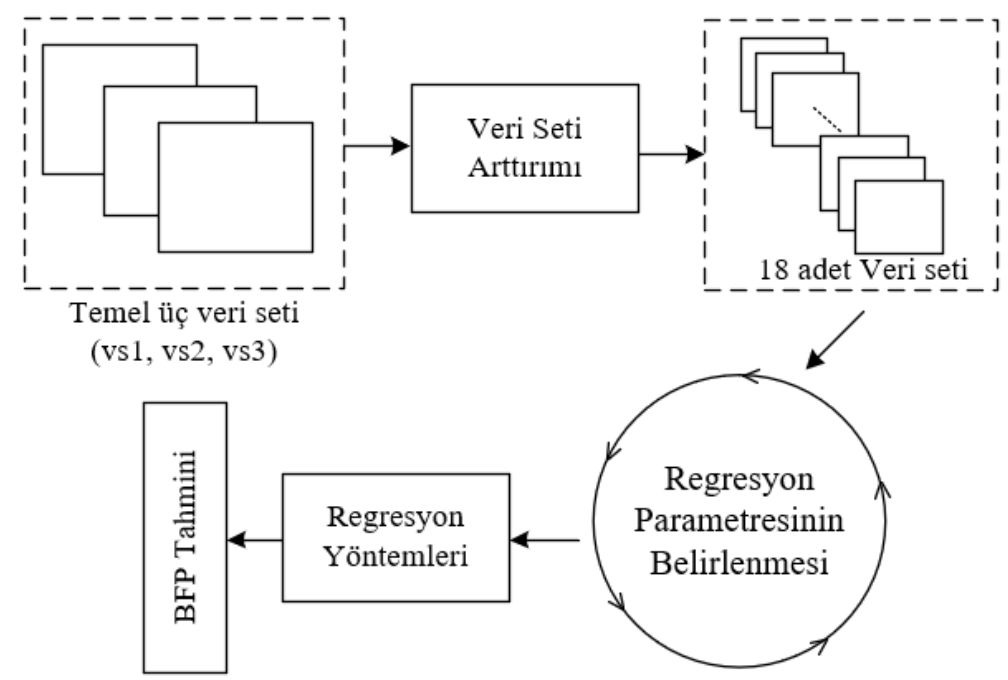

Şekil 3. Yöntemlere ait akış diyagramı

Tablo 2. Regresyon yöntemlerinin uygulandığı 18 veri setinin adları ve açıklamaları

\begin{tabular}{cccc}
\hline $\begin{array}{c}\text { Veri } \\
\text { Seti } \\
\text { Adı }\end{array}$ & $\begin{array}{c}\text { Uygulama } \\
\text { Veri Seti }\end{array}$ & $\begin{array}{c}\text { Özellik } \\
\text { Sayısı }\end{array}$ & $\begin{array}{c}\text { Veri Setinin } \\
\text { Açlklaması }\end{array}$ \\
\hline S1 & vs1 & 13 & Orijinal veri seti \\
\hline S2 & vs2 & 25 & Istatiksel yeni özellikler \\
\hline S3 & vs3 & 38 & vs1+vs2 veri seti \\
\hline S4 & vs1 & 2 & PCA bileşenleri \\
\hline S5 & vs2 & 2 & PCA bileşenleri \\
\hline S6 & vs3 & 2 & PCA bileşenleri \\
\hline S7 & vs1 & 4 & PCA bileşenleri \\
\hline S8 & vs2 & 4 & PCA bileşenleri \\
\hline S9 & vs3 & 4 & PCA bileşenleri \\
\hline S10 & vs1 & 2 & F-skor ile elde edilen özellikler \\
\hline S11 & vs1 & 4 & F-skor ile elde edilen özellikler \\
\hline S12 & vs1 & 6 & F-skor ile elde edilen özellikler \\
\hline S13 & vs2 & 2 & F-skor ile elde edilen özellikler \\
\hline S14 & vs2 & 4 & F-skor ile elde edilen özellikler \\
\hline S15 & vs2 & 6 & F-skor ile elde edilen özellikler \\
\hline S16 & vs3 & 2 & F-skor ile elde edilen özellikler \\
\hline S17 & vs3 & 4 & F-skor ile elde edilen özellikler \\
\hline S18 & vs3 & 6 & F-skor ile elde edilen özellikler \\
\hline
\end{tabular}

Son adımda antropometrik ölçümler ile BFP arasındaki ilişki istatistiksel olarak analiz edilmiştir. Bu şekilde orijinal özelliklerin, türetilen özelliklerin, her iki özellik setinin birleştirilmesiyle oluşturulan toplam özelliklerin, PCA ile elde edilen temel bileşenlerin ve BPF ile ilintisi yüksek olan özellikler ile oluşturulan tüm veri setinin başarımları karşılaştırılmıştır. 


\section{A. REGRESYON PARAMETRELERI VE KARŞILAŞTIRMA METRÍKLERI}

Parametre ayarları ve doğrulama için, sırasıyla çapraz doğrulama ile grid arama teknikleri bir arada kullanılmıştır [39]. Regresyon yöntemlerinin başarım testi için literatürde sıklıkla kullanılan karşılaştırma metrikleri kullanılmıştır.

Sonuçlara göre, SVR ve RF yöntemlerine ait parametreler Tablo 3 ve Tablo 4'deki gibi belirlenmiştir:

Tablo 3. SVR yöntemi sonuçlarının alınmasında kullanılan parametreler

\begin{tabular}{cccc}
\hline Veri Seti Adı & $\begin{array}{c}\text { Regülasyon } \\
\text { Parametresi }\end{array}$ & $\begin{array}{c}\text { SVR } \\
\text { Çekirdeği }\end{array}$ & $\begin{array}{c}\text { Gamma } \\
\text { Parametresi }\end{array}$ \\
\hline vs1 & 1100 & RBF & 0,1 \\
\hline vs2 & 2000 & RBF & 0,0001 \\
\hline vs3 & 0.1 & RBF & 0,001 \\
\hline
\end{tabular}

Tablo 4. RF yöntemi sonuçlarının alınmasında kullanılan parametreler

\begin{tabular}{ccccc}
\hline Veri Seti Adı & Ăgaç sayısı & $\begin{array}{c}\text { Max. Ăgaç } \\
\text { Derinliği }\end{array}$ & $\begin{array}{c}\text { Min. Düğüm } \\
\text { Bölücü Sayısı }\end{array}$ & $\begin{array}{c}\text { Yaprak Düğümde Min. } \\
\text { Örnek Sayısı }\end{array}$ \\
\hline vs1 & 391 & 50 & 5 & 1 \\
\hline vs2 & 500 & 50 & 5 & 4 \\
\hline vs3 & 64 & 100 & 2 & 2 \\
\hline
\end{tabular}

SVM ve RF yöntemlerinin başarım kriterleri belirmek amacıyla literatürde sıklıkla kullanılan, ortalama mutlak yüzde hatasl (MAPE), ortalama karesel hata (RMSE), medyan mutlak hata (MAE), determinasyon katsayısı (R2), korelasyon katsayısı (R) kullanılmaktadır. Ayrıca veri setinin \%80'i eğitim için, \%20'si test ve skorlar için ayrılmıştır.

Deneylerimizde kullanılan vücut yağ veri setlerinin ölçeği dikkate alınarak, karşılaştırılan regresyon modellerinin performansını değerlendirmek için beş kat çapraz doğrulama uygulanmaktadır. Beş kat çapraz doğrulamada ise ile $\mathrm{N}$ numuneli bir veri seti verildiğinde, her setin $\mathrm{N} / 5$ numunesi test için ve geri kalanı eğitim için kullanılmıştır. Veriler rastgele veri setinden seçilmiş ve her deney $20 \mathrm{kez}$ tekrarlanmıştır. Ardından nihai sonuç için ortalama alma işlemi gerçekleştirilmiştir.

R2, model tarafindan görünmeyen örneklerin ne kadar iyi tahmin edilebileceğinin bir ölçüsünü sağlar. $\mathrm{n}$ veri sayısı, $\bar{y}$ gerçek çıkış değerlerinin aritmetik ortalaması ve $\hat{y}_{i}$, i. çıkış örneği $y_{i}$ 'nin tahmini olmak üzere R2, Eşt15.'deki denklem ile ifade edilir.

$$
R^{2}(y, \hat{y})=1-\frac{\sum_{i=1}^{n}\left(y_{i}-\hat{y}_{i}\right)^{2}}{\sum_{i=1}^{n}\left(y_{i}-\bar{y}\right)^{2}}
$$

Eşt. 16 ile formüle edilen MAE, mutlak hata kaybının veya 11-norm kaybının beklenen değerine karşılık gelen bir risk ölçütüdür.

$$
\operatorname{MAE}(y, \hat{y})=\frac{1}{n} \sum_{i=1}^{n}\left|y_{i}-\hat{y}_{i}\right|
$$

MSE ve RMSE hata veya kaybın beklenen değerine karşıllk gelen bir risk ölçütüdür ve sırasıyla Eşt. 17 ve Eşt. 18 ile hesaplanmaktadır. 


$$
\begin{aligned}
& \operatorname{MSE}(y, \hat{y})=\frac{1}{n} \sum_{i=1}^{n}\left(y_{i}-\widehat{y}_{i}\right)^{2} \\
& \operatorname{RMSE}(y, \hat{y})=\sqrt{\frac{1}{n} \sum_{i=1}^{n}\left(y_{i}-\widehat{y}_{i}\right)^{2}}
\end{aligned}
$$

\section{B. DENEYSEL SONUÇLAR}

$\mathrm{Bu}$ çalışmada, kişilerden elde edilen antropometrik veri seti ile BFP oranın RF ve SVR yöntemleri ile tespit edilmesi amaçlanmıştır. 13 özellikli bir veri setinin, başarım performansını arttırabilmek adına özellik sayısında bir artırıma gidilmesi hedeflenmiştir. Ancak yeni eklenecek özelliklerin, orijinal özellikleri doğru temsil edebilmesi ve ilişkileri daha iyi ortaya göstermesi gerekmektedir. Bu nedenle orijinal özellikler ve önerilen istatistiki yöntemler kullanılarak (Tablo 1 [X14-X38]) yeni bir veri seti oluşturulmuştur. $\mathrm{Bu}$ veri seti orijinal özellikleri içermemekte ve tamamen istatistiksel yöntemler kullanılarak elde edilmektedir. Orijinal veri seti, oluşturulan yeni veri seti ve her iki veri setinin birleşiminden oluşturulan üç veri seti ile RF ve SVR testleri gerçekleştirilmiştir. Ayrıca her veri setine özellik azaltma ve seçme teknikleri kullanılarak deneyler gerçekleştirilmiştir. Bu amaçla iki yöntem seçilmiştir. Birincisi PCA ve ikinci TDDG analizidir. PCA ile tüm özellikleri barındıracak temel bileşenler belirlenerek, TDDG ile BFP oranı ile ilintili olan en iyi özellikler seçilerek deneyler gerçekleştirilmiştir. RF ve SVR yöntemine ait doğru parametreler, çapraz doğrulama ve grid arama teknikleri kullanılarak elde edilmiştir.

Tablo 5 ve Tablo 6' da deney sonuçları verilmiştir. SVR ile yapılan 18 eğitimden, orijinal veri setiS1ve S1'den türetilen S2 ve S3 veri setleriyle yapılan regresyonlar, BFP değeri ile yüksek ilintili özelliklerle eğitilmiş deneylere oranlara daha düşük başarım sonuçları ürettiği gözlemlenmiştir. S1 ve S2, S3 özellik sayısı en fazla olan veri setleridir. Ancak barındıkları bazı özellikler BFP ile zit korelasyona sahiptir. Bu nedenle BFP ile doğrusal olan özellikler ile yapılan deneyler doğru tahmin değerleri vermektedir. Öncelikle sonuç tablolarındaki SVR1 deneyi, orijinal özellikleri içeren deney seti iken, SVR3 deneyi ise en büyük özellik sayısına sahip veri setinden gerçekleştirilen deneylerdir. SVR18 adlı deney, sadece en iyi 6 F-skor değerine sahip özelliklerle gerçekleştirilen deney olmasına rağmen en iyi SVR sonucunu vermektedir. Benzer şekilde SVR 17 adlı deney, en iyi ikinci başarılı sonucu ürettiği gözlemlenebilir. Sirasıyla SVR 17 ve SVR1 8 deneyleri, 38 özellikli veri setlerinden elde edilen 4 ve 6 özellikli veri setleri olmasına karşın, sadece 13 (vs1) özellikli orijinal veri setinden elde edilen en iyi 6 ve 4 F-skor değerine sahip SVR12 ve SVR11 adlı deneylerde başarılı sonuçlar ürettiği tespit edilmiştir. Verilen açılklamaların sayısal olarak örneklendirmek istersek en iyi RMSE sonuçları SVR18, SVR17 ve SVR12 deneyleri için sırasıyla, 3,1741, 3,4366 ve 3,5378dir, benzer bir şekilde R2 sonuçları SVR18, SVR17 ve SVR11 deneyleri için sırasıyla, $0,823,0,7925$ ve 0,7763 olmaktadır. SVR sonuçlarından, en düşük eğitim sonucunu veren deneyler, orijinal veri seti ile yapılan SVR1 deneyi ile türetilmiş veri seti vs2'ye PCA yöntemi uygulanarak temel 2 bileşen içeren SVR8 adlı deneydir. Ancak SVR2 deney sonuçları için bir parantez açmak gerekir. SVR2 deneyi, orijinal veri setinden hiçbir özellik içermemektedir. Buna karşın, deneyde ulaşılan sonuçlar diğer deneylere nazaran tatmin edicidir.

Tablo 5'den elde edilen SVR sonuçlarından faydalanılarak BFP değerinin tespitinde SVR ile yapılan eğitimler için çıkarılabilecek sonuç; orijinal veri seti ile yapılan eğitimler, kendisinden türetilen yeni özellikli test verileri ile yapılan eğitimlerden daha düşük verebilmektedir. Ayrıca hem orijinal veri setinden hem de türetilen veri setinden elde edilen belli sayıda en iyi F-skor değerine sahip özelliklerle yapılan deneyler en başarılı sonuçları vermektedir. Ayrıca PCA yöntemi ile elde edilen özelliklerle yapılan eğitimlerin başarımlarının, bazı metrikler bakımından diğer deneylerden düşük olduğu tespit edilmiştir.

RF yöntemi ile yapılan deneylerin başarım sonuçları Tablo 6 ile verilmiştir ve SVR yöntemi ile yapılan eğitimlere göre çok farklı sonuçlar göstermektedir. Örneğin RF yöntemi ile yapılan deneylerde, temel 
bileşenler ile F-skor değeri yüksek olan özellikler seçilerek yapılan eğitimler, orijinal özelliklerle yapılan eğitimden başarılı sonuç vermemiştir. Bu durum SVR ile yapılan deneylerde tersi olduğu görülmektedir. Örnek olarak, RF1, RF2 ve RF3 adlı deneylerde yap1lan tüm eğitimler, diğer deneylerden daha başarılı çıktılar üretmiştir. Ancak RF2'nin başarımı dikkat çekmektedir. S2 veri setindeki özellikler, orijinal özelliklerin hiçbirini içermemektedir ancak orijinal verilerden elde edilen bir eğitim veri setiydi. Niceliksel olarak bu durum örneklenir ise, en yüksek ve en düşük tahmin doğruluğunu veren deneyler sirasiyla RF2 ve RF10 adlı deneylerdir. Sirasiyla RMSE'de 2,2519 ile 5,4905, MAE'de 2,006 ile 4,7847, R2'de 0,9267 ile 0,2097 gibi sonuçlar elde edilmiştir. En iyi üç sonucu veren deneyler dışında, orijinal veri setinin F-skor değeri en yüksek olan 2 özelliğini kullanan S10 veri seti de dikkat çekmektedir. Dolasıyla RF yöntemi için üretilebilecek yeni veri setlerinin, orijinal veri setine göre daha başarılı sonuçlar verebileceği kanaatine varılabilir. Örneğin, RMSE değeri en düşük olan ilk 4 deney RF1, RF2, RF3 ve RF10 için sırasıyla 2,2519, 2,4389, 2,4974 ve 2,4982 değerlerine ulaşılmıştır.

Tablo 5. SVR performans sonuçlart

\begin{tabular}{llccccc}
\hline Deney Adı & $\begin{array}{l}\text { Uygulama } \\
\text { Veri Seti }\end{array}$ & RMSE & MSE & MAE & R2 & R \\
\hline SVR1 & S1 & 4,5806 & 20,9818 & 3,793 & 0,532 & 0,7757 \\
\hline SVR2 & S2 & 3,5711 & 12,7528 & 2,9465 & 0,7748 & 0,8755 \\
\hline SVR3 & S3 & 3,5593 & 12,6685 & 2,9239 & 0,7763 & 0,8911 \\
\hline SVR4 & S4 & 4,1497 & 17,2201 & 3,4903 & 0,6773 & 0,774 \\
\hline SVR5 & S5 & 4,1871 & 17,532 & 3,4533 & 0,6904 & 0,8639 \\
\hline SVR6 & S6 & 4,2826 & 18,3407 & 3,5566 & 0,6761 & 0,8637 \\
\hline SVR7 & S7 & 3,8922 & 15,1492 & 3,2427 & 0,7325 & 0,8863 \\
\hline SVR8 & S8 & 5,2748 & 27,8231 & 4,2458 & 0,3674 & 0,7506 \\
\hline SVR9 & S9 & 4,6506 & 21,6279 & 3,7928 & 0,5231 & 0,7548 \\
\hline SVR10 & S10 & 3,6788 & 13,5334 & 3,1146 & 0,761 & 0,881 \\
\hline SVR11 & S11 & 3,5589 & 12,6654 & 3,015 & 0,7763 & 0,8962 \\
\hline SVR12 & S12 & 3,5378 & 12,5159 & 2,9994 & 0,779 & 0,8772 \\
\hline SVR13 & S13 & 6,1539 & 37,8704 & 4,8844 & 0,132 & 0,5222 \\
\hline SVR14 & S14 & 4,6244 & 21,385 & 3,764 & 0,5285 & 0,7273 \\
\hline SVR15 & S15 & 3,8982 & 15,1956 & 3,308 & 0,697 & 0,8226 \\
\hline SVR16 & S16 & 3,6314 & 13,1872 & 2,8897 & 0,7683 & 0,8948 \\
\hline SVR17 & S17 & 3,4366 & 11,8099 & 2,7079 & 0,7925 & 0,8932 \\
\hline SVR18 & S18 & 3,1741 & 10,0747 & 2,4865 & 0,823 & 0,8756 \\
\hline
\end{tabular}

Tablo 6. RF performans sonuçları

\begin{tabular}{llccccc}
\hline Deney Adı & $\begin{array}{l}\text { Uygulama } \\
\text { Veri Seti }\end{array}$ & RMSE & MSE & MAE & R2 & R \\
\hline RF1 & S1 & 2,4389 & 5,9483 & 1,747 & 0,9197 & 0,9654 \\
\hline RF2 & S2 & 2,2519 & 5,0712 & 2,006 & 0,9267 & 0,9673 \\
\hline RF3 & S3 & 2,4974 & 6,237 & 2,226 & 0,9099 & 0,968 \\
\hline RF4 & S4 & 3,6101 & 13,0325 & 2,873 & 0,7964 & 0,8586 \\
\hline RF5 & S5 & 3,1271 & 9,779 & 2,7175 & 0,8106 & 0,9308 \\
\hline RF6 & S6 & 3,2379 & 10,484 & 2,6975 & 0,8156 & 0,8909 \\
\hline RF7 & S7 & 2,9029 & 8,4268 & 2,206 & 0,8779 & 0,886 \\
\hline RF8 & S8 & 3,3129 & 10,9754 & 2,748 & 0,7949 & 0,8525 \\
\hline
\end{tabular}


Tablo 6. (devam) RF performans sonuçları

\begin{tabular}{llccccc}
\hline Deney Adı & $\begin{array}{l}\text { Uygulama } \\
\text { Veri Seti }\end{array}$ & RMSE & MSE & MAE & R2 & R \\
\hline RF9 & S9 & 2,7738 & 7,6941 & 2,2515 & 0,8069 & 0,9252 \\
\hline RF10 & S10 & 2,4982 & 6,2411 & 1,859 & 0,9154 & 0,9489 \\
\hline RF11 & S11 & 2,6986 & 7,2823 & 2,2325 & 0,8808 & 0,9203 \\
\hline RF12 & S12 & 2,7571 & 7,6017 & 2,4592 & 0,8756 & 0,9398 \\
\hline RF13 & S13 & 5,4905 & 30,1455 & 4,7847 & 0,2097 & 0,5656 \\
\hline RF14 & S14 & 2,9058 & 8,4439 & 2,3745 & 0,8599 & 0,9206 \\
\hline RF15 & S15 & 3,0469 & 9,2837 & 2,369 & 0,8658 & 0,9183 \\
\hline RF16 & S16 & 2,6897 & 7,2347 & 1,9757 & 0,8456 & 0,8887 \\
\hline RF17 & S17 & 2,8125 & 7,91 & 2,2205 & 0,8857 & 0,9153 \\
\hline RF18 & S18 & 2,4808 & 6,1544 & 1,8765 & 0,911 & 0,9605 \\
\hline
\end{tabular}

\section{IV.SONUC}

BFP oranın tahmininde, RF yönteminin SVR yönteminden karşılaştırma metrikleri bakımından daha üstün olduğu tespit edilmiştir. Şekil 4'te SVR ve RF yöntemlerinin verilen metriklere göre her birisine ait en iyi sonuç üreten ilk 3 sonuç gösterilmektedir. Şekil 4 (a) ve Şekil 4 (b)'de RMSE ve MSE metriklerinde RF2 deneyi, Şekil 4 (c)'de MAE metriğinde RF1 deneyi, Şekil (4)'de MAE metriğinde RF2 deneyi ve Şekil 4 (e)'de R metriğinde RF2 deneyi BPF değerini en iyi tahmin eden deneyler olduğu görülmektedir.

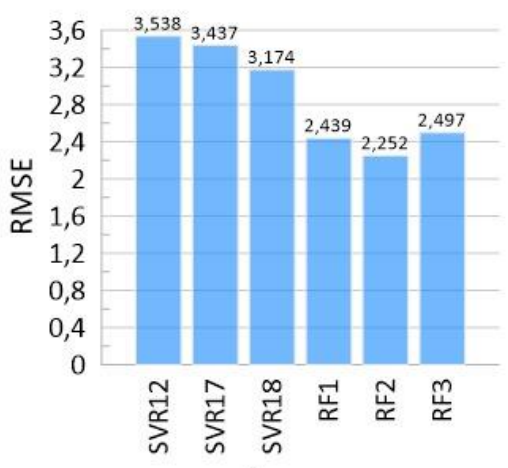

(a)

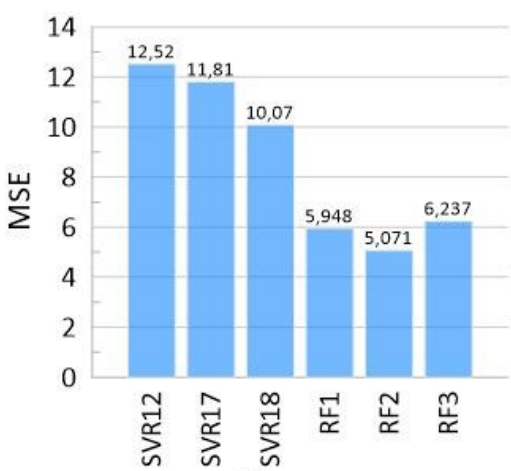

(b)

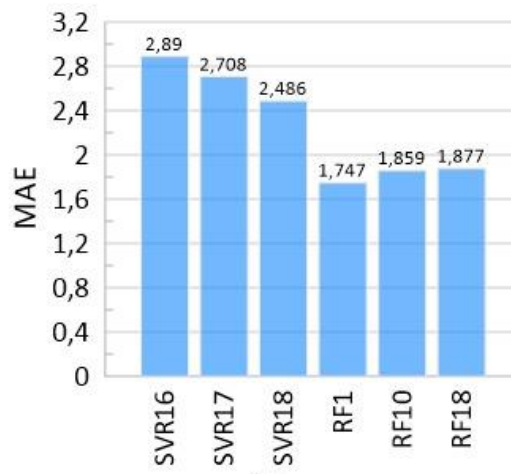

(c)

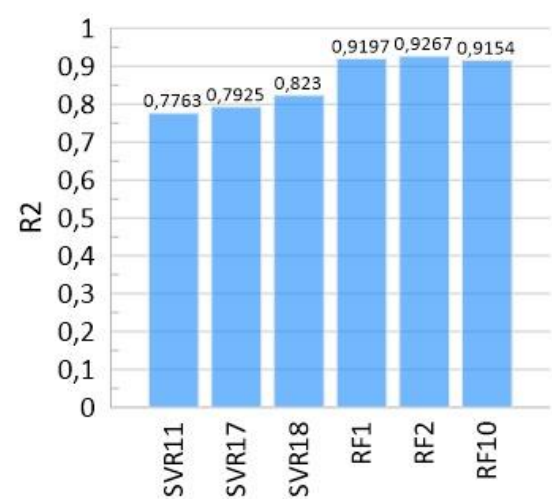

(d)

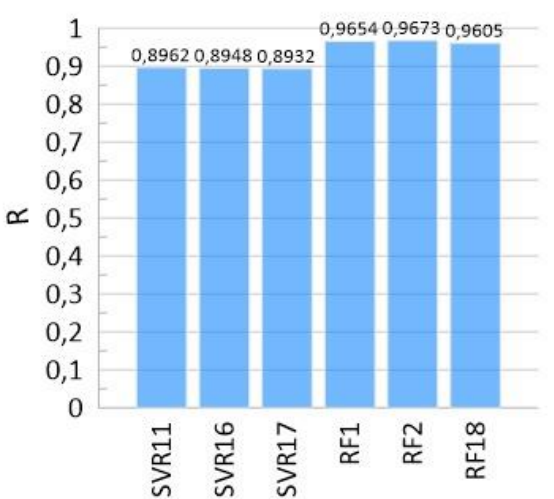

(c)

Şekil 4. SVR ve RF deneylerindeki en iyi 3 performansın karşılaştırılması 
Şekil 4.a'da verilen RMSE kıstası bakımından, istatiksel olan özellikler (önerilen istatistiki yöntemler ile oluşturulan vs2 veri seti, 25 özellikli) ile gerçekleştirilen RF deneyi 2,252 ile en iyi tahmin skoruna sahip iken, SVR ile yapılan deneylerde 38 özellikli (vs1+vs2) veri setinden elde edilen en iyi 6 F-skor değerine sahip özellikler ile gerçekleştirilen deney 3,174 skor değerine ulaşılmıştır. MSE kriteri bakımından başarım değerleri, RMSE başarım değerleri ile benzer olacağı aşikardır.

Şekil 4.c'de MAE değerleri için, RF1 uygulanmasında, orijinal veri setinde (vs1) en iyi skor değerine ulaşılmıştır. Ancak orijinal veri setinden elde edilen ve sadece en iyi 2 F-skor değeri olan özellikler ile gerçekleştirilen RF10 deneyi, neredeyse RF1 deneyi kadar etkili olduğu görülmektedir. RF1 ve RF10 için sırasıyla 1,747 ve 1,859 skor değerleri elde edilmiştir. MAE için, SVR tahminlerinde, en geniş veri setinde (vs3 veri seti, 35 özellikli) F-skor değerleri için yapılmış deneylerin tahmin değerleri göze çarpmaktadır. En iyi 6, 4 ve 2 sayıda F-skor değerine sahip özellikler ile yapılan deneylerde sırasıyla 2,486, 2,708 ve 2,89 değerlerine ulaşılmıştır.

RF deneylerinde Şekil 4.d'de verilen R2 kıstasına göre, orijinal ve türetilen yeni veri seti ile gerçekleştirilen tahminlerin (RF1 ve RF2 deneyleri) başarım oranlarının yüksek olduğu tespit edilmiştir. Ancak orijinal veri setine ait en iyi 2 F-skor değeri ile elde edilen özellikler ile yapılan deney (RF10) neredeyse orijinal veri seti ile yapılan deneye eşdeğerdir. SVR deneyleri için ise, 35 özellikli (vs3 yani orijinal ve türetilen veri setlerinin birleşimi) veri setlerinden elde edilen en iyi 4 ve 6 özellikli veri setlerinin başarımı diğer SVR deneylerinden yüksektir. R kriteri bakımından başarım değerleri, R2 başarım değerleri ile benzerdir.

Önerilen yöntemlerin, literatürde yer alan diğer çalışmalar ile başarım karşılaştırması Tablo 7'de verilmiştir. Tabloda verilen tüm çalışmalarda, [31] çalışmasından elde edilen antropometrik veri seti üzerinde yöntemler uygulanmıştır. SVR yöntemine yeni bir parametre eklenerek yeni bir yöntem olarak sunulan IRE-SVM [23] ile yapılan BFP tahmin sonuçları Tablo 7'de ilk sırada verilmiştir. Tablonun 2 ile 6 arasındaki sonuçlar, hibrit makine öğrenmesi yöntemleri uygulanarak elde edilmiştir [27]. 7 ve 8 satırdaki sonuçlar, standart RF ve SVM parametreleri ile elde edilmiştir. 9 ile 13 arasındaki sonuçlar, bu çalışmadan elde edilen en iyi tahmin sonuçların ulaşıldığı deneylerdir. Tabloda boş olarak verilen sonuç değerleri ilgili çalışmalardan elde edilememektedir.

Tablo 7. Literatür ile karşılaş̧ırma

\begin{tabular}{lllcccc}
\hline Sira & $\begin{array}{l}\text { Literatür çalışmaları ve } \\
\text { önerilen yöntemler }\end{array}$ & $\begin{array}{l}\text { Uygulama } \\
\text { Veri Seti }\end{array}$ & RMSE & MAE & R & R2 \\
\hline 1 & [23]-IRE-SVM & S1 & 4,4334 & 3,6261 & - & - \\
\hline 2 & [27]-MLFNN & S1 & 8,535 & - & 0,451 & 0,203 \\
\hline 3 & [27]-MLFNN+DT & S1 & 5,832 & - & 0,656 & 0,43 \\
\hline 4 & [27]-MLFNN+SVM & S1 & 5,662 & - & 0,631 & 0,398 \\
\hline 5 & [27]-DT+SVM & S1 & 4,817 & - & 0,74 & 0,547 \\
\hline 6 & [27]-MLFNN+DT+SVM & S1 & 11,33 & - & 0,717 & 0,514 \\
\hline 7 & Standart SVR & S1 & 5,32 & 4,17 & 0,69 & 0,47 \\
\hline 8 & Standart RF & S1 & 4,218 & 3,826 & 0,7652 & 0,548 \\
\hline 9 & SVR1 & S1 & 4,5806 & 3,793 & 0,7757 & 0,532 \\
\hline 10 & SVR18 & S18 & 3,174 & 2,486 & 0,8756 & 0,823 \\
\hline 11 & RF1 & S1 & 2,4389 & $\mathbf{1 , 7 4 7}$ & 0,9654 & 0,9197 \\
\hline 12 & RF2 & S2 & $\mathbf{2 , 2 5 1 9}$ & 2,006 & 0,9267 & $\mathbf{0 , 9 6 7 3}$ \\
\hline 13 & RF18 & S18 & 2,4808 & 1,8765 & 0,9605 & 0,911 \\
\hline
\end{tabular}

Karşılaştırma metrikleri bakımından, istatiski yöntemler kullanılarak elde edilen yeni veri seti ile yapılan RF deneyi (Tablo 7, satır 12) en başarılı performansı göstermiş̧tir. Benzer şekilde hem orijinal hem de türetilen veri setlerinin birleşimden oluşturulan veri setinden elde edilen sadece 6 özellikli veri setinde (Tablo 7, satır 13) başarılı tahmin sonuçlarına ulaşılmıştır. En iyi performans sonuçları olarak RMSE, MAE, R2 başarım kriterleri bakımından sırasıyla RF2 deneyinde 2,2519, RF1 deneyinde 1,747 ve RF2 
deneyinde 0,9673 değerleri elde edilmiştir. SVR yöntemlerinde, [23] çalışmasında RMSE değeri 4,4334, standart SVR deneyinde 5,32 ve SVR18 deneyinde 3,174 değerlerine ulaş1lmıştır. SVR18 deneyi, 38 özellikli türetilmiş veri setinden elde edilen en iyi 6 F-skor değerine sahip özellikler ile oluşturulmuş veri setine SVR uygulanmış bir deneydir.

BFP değerinin, SVR ve RF yöntemleriyle tahmininde oldukça başarılı sonuçlara ulaşılmaktadır. 13 özellikli 252 veriye sahip bir veri setinde regresyon yöntemleri ile BFP değeri yüksek doğrulukta tahmin edilebildiği görülmektedir. Ancak RF yöntemi, SVR yöntemlerine nazaran daha doğru tahmin değerlerine ulaştığı sonuçlardan görülmektedir. Ayrıca bir veri setinden üretilebilecek yeni veri setlerinin ve veri setlerine uygulanabilecek özellik seçme yöntemleri ile oluşturulacak yeni veri setlerinin başarılı çıktılar üreteceği bu çalışmada gösterilmiştir.

\section{KAYNAKLAR}

[1] F. McLellan, "Obesity rising to alarming levels around the world," The Lancet, c. 359, s. 9315, ss. 1412, 2002.

[2] C. L. Edelman, C. L. Mandle ve E. C. Kudzma, Health Promotion Throughout the Life Span-EBook, 9. bask1, Missouri, United States of America: Elsevier Health Sciences, 2017, böl. 2, ss. 23-24.

[3] I. G. Polat, "Effect of Er stress and Sik2 Reciprocal relationship on human precursor fat cell (LiSa-2) differentiation," Doktora Tezi, Gebze Teknik Üniversitesi, Kocaeli, Türkiye, 2017.

[4] F. Ortega, C. Lavie ve S. Blair, "Obesity and cardiovascular disease," Circulation Research, c. 118, s. 11, ss. 1752-1770, 2016.

[5] C. Lavie, A. Schutter, P. Parto, E. Jahangir, P. Kokkinos, F. Ortega, R. Arena ve R. Milani, "Obesity and prevalence of cardiovascular diseases and prognosis - the obesity paradox updated," Progress in Cardiovascular Diseases, c. 58, s. 5, ss. 537-547, 2016.

[6] A. Keys, F. Fidanza, M. Karvonen, N. Kimura ve H. Taylor, "Indices of relative weight and obesity," Journal of Chronic Diseases, c. 25, s. 6-7, ss. 329-343, 1972.

[7] R. Huxley, S. Mendis, E. Zheleznyakov, S. Reddy ve J. Chan, "Body mass index, waist circumference and waist:hip ratio as predictors of cardiovascular risk," Obesity and Metabolism, c. 8, s. 1, ss. 69-69, 2011.

[8] C. Lee, R. Huxley, R. Wildman ve M. Woodward, "Indices of abdominal obesity are better discriminators of cardiovascular risk factors than BMI: A meta-analysis," Journal of Clinical Epidemiology, c. 61, s. 7, ss. 646-653, 2008.

[9] B. Srdić, B. Obradović, G. Dimitrić, E. Stokić ve S. Babović, "Relationship between body mass index and body fat in children - age and gender differences," Obesity Research \& Clinical Practice, c. 6, s. 2, ss. 167-173, 2012.

[10] A. Kupusinac, E. Stokić ve R. Doroslovački, "Predicting body fat percentage based on gender, age and BMI by using artificial neural networks," Computer Methods and Programs in Biomedicine, c. 113, s. 2, ss. 610-619, 2014. 
[11] P. Deurenberg ve M. Yap, "The Assessment of Obesity: Methods for measuring body fat and global prevalence of obesity," Best Practice \& Research Clinical Endocrinology \& Metabolism, c. 13, s. 1, ss. 1-11, 1999.

[12] N. Jensky-Squires, C. Dieli-Conwright, A. Rossuello, D. Erceg, S. McCauley ve E. Schroeder, "Validity and reliability of body composition analysers in children and adults," British Journal of Nutrition, c. 100, s. 4, ss. 859-865, 2008.

[13] W. Beeson, M. Batech, E. Schultz, L. Salto, A. Firek, M. Deleon, H. Balcazar ve Z. CorderoMacintyre, "Comparison of body composition by bioelectrical impedance analysis and dual-energy Xray absorptiometry in hispanic diabetics," International Journal of Body Composition Research, c. 8, s. 2, ss. 45-50, 2010.

[14] A. M. Bongiolo, K. Castro ve M. A. da Silva. "Bioelectrical 1mpedance analysis: body composition in children and adolescents with Down Syndrome," Minerva Pediatrica, c. 69, s. 6, ss. 560$563,2017$.

[15] D. Anblagan, R. Deshpande, N. Jones, C. Costigan, G. Bugg, N. Raine-Fenning, P. Gowland ve P. Mansell, "Measurement of fetal fatin uteroin normal and diabetic pregnancies using magnetic resonance 1maging," Ultrasound in Obstetrics \& Gynecology, c. 42, s. 3, ss. 335-340, 2013.

[16] J. Josefson, M. Nodzenski, O. Talbot, D. Scholtens ve P. Catalano, "Fat mass estimation in neonates: anthropometric models compared with air displacement plethysmography," British Journal of Nutrition, c. 121, s. 3, ss. 285-290, 2019.

[17] D. Fukuda, M. Wray, K. Kendall, A. Smith-Ryan ve J. Stout, "Validity of near-1nfrared interactance (FUTREX 6100/XL) for estimating body fat percentage in elite rowers," Clinical Physiology and Functional Imaging, c. 37, s. 4, ss. 456-458, 2017.

[18] A. Fernández-Sánchez, E. Madrigal-Santillán, M. Bautista, J. Esquivel-Soto, Á. MoralesGonzález, C. Esquivel-Chirino, I. Durante-Montiel, G. Sánchez-Rivera, C. Valadez-Vega ve J. A. Morales-González, "Inflammation, oxidative stress, and obesity," International Journal of Molecular Sciences, c. 12, s. 5, ss. 3117-3132, 2011.

[19] T. Ferenci, "Two Applications Of Biostatistics in The Analysis of Pathophysiological Processes," Doktora Tezi, Óbuda Univeristy, Budapest, Hungary, 2013.

[20] T. Ferenci ve L. Kovács, "Predicting body fat percentage from anthropometric and laboratory measurements using artificial neural networks," Applied Soft Computing, c. 67, ss. 834-839, 2018.

[21] S. Balasundaram, "On lagrangian support vector regression," Expert Systems with Applications, c. 37 , s. 12 , ss. $8784-8792,2010$.

[22] Y. Xu ve L. Wang, "A weighted twin support vector regression," Knowledge-Based Systems, c. 33, ss. 92-101, 2012.

[23] R. Chiong, Z. Fan, Z. Hu ve F. Chiong, "Using an improved relative error support vector machine for body fat prediction," Computer Methods and Programs in Biomedicine, c. 198, ss. 105749, 2020. 
[24] P. Deurenberg, M. Yap ve W. van Staveren, "Body mass index and percent body fat: a meta analysis among different ethnic groups," International Journal of Obesity, c. 22, s. 12, ss. 1164-1171, 1998.

[25] A. Jackson P. Stanforth, J. Gagnon, T. Rankinen, A. Leon, D. Rao, J. Skinner, C. Bouchard ve J. Wilmore, "The Effect of sex, age and race on estimating percentage body fat from body mass index: the heritage family study," International Journal of Obesity, c. 26, s. 6, ss. 789-796, 2002.

[26] Y. Shao, "Body fat percentage prediction using intelligent hybrid approaches," The Scientific World Journal, c. 2014, ss. 1-8, 2014.

[27] M. Uçar, Z. Uçar, F. Köksal ve N. Daldal, "Estimation of body fat percentage using hybrid machine learning algorithms," Measurement, c. 167, ss. 108173, 2020.

[28] K. DeGregory, P. Kuiper, T. DeSilvio, J. D. Pleuss, R. Miller, J. W. Roginski, C. B. Fisher, D. Harness, S. Viswanath, S. B. Heymsfield, I. Dungan ve D. M. Thomas, "A review of machine learning in obesity," Obesity Reviews, c. 19, s. 5, ss. 668-685, 2018.

[29] M. Akman, M. K. Uçar, Z. Uçar, K. Uçar, B. Baraklı ve M. R. Bozkurt, "Determination of body fat percentage by gender based with photoplethysmography signal using machine learning algorithm," Innovation and Research in BioMedical Engineering, Basımda.

[30] C. Cortes ve V. Vapnik, "Support-vector networks," Machine learning, c. 20, s. 3, ss. 273-297. 1995.

[31] T. K. Ho, "Random decision forests", In: Proceedings of 3rd International Conference on Document Analysis and Recognition. IEEE, Montreal, QC, Canada, 1995, ss. 278-282.

[32] R. Johnson, "Fitting percentage of body fat to simple body measurements," Journal of Statistics Education, c. 4, s. 1, 1996.

[33] W. E. Siri, "body composition from fluid spaces and density: analysis of methods," University of Michigan Library, ss. 1-33, 1956.

[34] X. Yan ve S. Xiaogang, "Linear regression analysis: theory and computing," World Scientific, ss. 1-2, 2009.

[35] H. B. Curry, "The method of steepest descent for non-linear minimization problems," Quart. Appl. Math., s. 2, ss. 258-261, 1944.

[36] S. Boyd ve L. Vandenberghe, "Convex Optimization", 7. bask1, Newyork, United States of America: Cambridge University Press, 2004, böl. 5, ss. 215-216

[37] L. Breiman, J. Friedman, C. J., Stone ve R. A. Olshen, "Classification and Regression Trees," 1. bask1, London, England: CRC Press, 1984, böl. 11, ss. 246-259

[38] L. Breiman, "Random forests," Machine Learning, c. 45, s. 1, ss. 5-32, 2001.

[39] B. Schölkopf, "Statistical Learning and Kernel Methods", In: Data Fusion and Perception, G. Della Riccia, HJ. Lenz, R. Kruse, International Centre for Mechanical Sciences Book Series, 1. bask1, Vienna, Austria :Springer, 2001, böl. 431, ss. 3-24. 